\title{
Semiótica, Design e o Imaginário Construído sobre os Idosos
}

Semiotics, Design and the Imagery Built on the Elderly

RIBEIRO, Pryscila; Universidade do Estado de Minas Gerais

pryscilaribeiro@yahoo.com.br

ROMEIRO FILHO, Eduardo; Doutor; Universidade Federal de Minas Gerais romeiro@dep.ufmg.br

MENDONÇA, Rosângela Míriam L.O.; Doutora; Universidade do Estado de Minas Gerais/ Pósdoutoranda no Programa de Doutorado em Inovação Tecnológica e Biofarmacêutica da UFMG romiriam@arquicad.com.br

\section{Resumo}

Este artigo faz parte de uma pesquisa que investiga como a mídia constrói o perfil do idoso e o divulga para a sociedade, criando e alimentando um imaginário coletivo sobre o idoso. Ele apresenta a análise semiótica de um conjunto de anúncios publicitários de um mesmo segmento, o da indústria cervejeira. Os critérios utilizados partem da avaliação de características físicas, comportamentais, de seleção de elenco, vestuário e cenográficas que possam estabelecer conexão com o imaginário identificado sobre os idosos, explorando os pontos de vista qualitativoicônico, singular-indicativo e convencional-simbólico. Esta análise semiótica permitiu avaliar estereótipos e identificar importantes características sociais, do perfil do designer e formas de relacionamentos a serem estimuladas buscando contribuir para a eficiência nas atividades de Design.

Palavras Chave: Design, comunicação, semiótica, idosos, estereótipos, sustentabilidade.

\section{Abstract}

This article is part of a research that has investigates how the media builds the profile of the elderly and disseminates it to society by creating and nurturing a collective imagery on the elderly. It presents the semiotic analysis of a set of advertisements of the same segment, the brewing industry. The criteria used start from the evaluation of physical, behavioral, cast selection, costume and scenographic characteristics that could establish connection with the imagery identified on the elderly, exploring the qualitative-iconic, singular-indicative and conventional-symbolic points of view. This semiotic analysis has allowed to evaluate stereotypes and identify important characteristics of the society, of the designer profile and forms of relationships to be stimulated, aiming at contributing to the efficiency in Design activities.

Keywords: Design, communication, semiotics, elderly, stereotypes, sustainability.

\section{Agradecimentos:}

À FAPEMIG, pelo apoio à pesquisa tratada nesse artigo.

Ao Prof. André Borges, mestre em Teoria da Literatura e Sistemas Semióticos, pelas importantes contribuições para o desenvolvimento do projeto, base deste artigo. 


\section{Introdução}

O processo de envelhecimento e suas características tornaram-se atualmente um fator de grande importância para a sociedade, visto que este processo passou a ser realidade em todo o mundo. Segundo a United Nations (2009), já existem no mundo cerca de 600 milhões de pessoas acima dos 60 anos e em 2050 a população com essa faixa etária será de quase 2 bilhões (WHO, 2005; United Nations, 2009). Esses dados também podem ser visualizados no Brasil, onde a população idosa (pessoas com 60 anos ou mais) alcançou, no ano de 2013, 14,9 milhões de pessoas, e até o ano de 2060 deverá chegar a 58,4 milhões de idosos, representando $26,7 \%$ do total da população (IBGE, 2013).

O processo de envelhecimento mundial pode ser explicado pelo aumento da expectativa de vida populacional causado pela redução da taxa de fecundidade, diminuição da taxa de mortalidade e pela melhora na qualidade de vida decorrente dos avanços da medicina (MIRANDAMORENO; LEE-GOSSELIN, 2008; UFU, 2012).

É também possível observar em alguns países o crescimento da renda per capita do idoso nos últimos anos, levando a crer que eles serão um público consumidor em potencial (EUROMONITOR, 2013; KEARNEY, 2013). Sendo assim, esse enorme grupo caracterizado por pessoas acima dos 60 anos, será o principal consumidor durante as próximas décadas. Essa desestruturação demográfica terá como consequência diversas alterações no funcionamento da sociedade e assim, fabricantes e varejistas deverão reformar suas estruturas, adaptando seus produtos e meios de venda para melhor atender seus clientes e funcionários envelhecidos (KEARNEY, Op.Cit). Apesar disso, o sistema de marketing das empresas, em especial no que se refere à publicidade, muitas vezes ignora que estas mudanças estão ocorrendo, desconsiderando a oportunidade de atendimento a um grupo importante e crescente de consumidores. Da mesma forma, estas empresas não dirigem suas atividades de design ao atendimento das necessidades deste grupo de usuários.

Considerando-se aqui a definição de Kotler (1992) para o marketing, como "a atividade humana dirigida para a satisfação das necessidades e desejos, através dos processos de troca" entre empresas e clientes (ou usuários), percebe-se que o design utiliza de informações levantadas pelos departamentos de marketing das empresas, notadamente utilizados na elaboração de "briefings" de produtos. Neste caso, esta discussão cabe também ao design, no sentido do desenvolvimento de soluções adequadas aos usuários idosos. Conforme o último Relatório Mundial sobre o Envelhecimento e Saúde da Organização Mundial de Saúde (OMS), a população idosa está crescendo em todo o mundo e este é um segmento da sociedade economicamente importante sendo, por vezes, os consumidores de maior poder aquisitivo e disponibilidade de tempo (OMS, 2015).

Assim, torna-se necessário compreender a construção de uma tipologia da presença de pessoas idosas em publicidade e as consequências desta construção, em termos da produção do design e da eficiência da sua comunicação (ANTONIONI; MAZZOLI, 2014). Na medida em que se conhece melhor este público que cada vez mais é tão significativo para a nossa sociedade, não só em termos afetivos, mas em termos de movimentação de atividades econômicas, consegue-se maior eficiência dos trabalhos de comunicação e design desenvolvidos, seja do ponto de vista gráfico, quanto no desenvolvimento de produtos, serviços e ambientes. 


\section{Métodos de Análise}

O projeto atual foi baseado em dados compilados e analisados no trabalho anterior "Design e o Imaginário Construído sobre os Idosos" (PEREIRA; MENDONÇA, 2016) que avaliou 103 filmes publicitários selecionados. Esse material corresponde à totalidade dos comerciais relacionados aos idosos e seu imaginário, veiculados nos canais de maior audiência e representativos da realidade televisiva nacional, em um período representativo da programação habitual. Dentro desse acervo, os anúncios da categoria "bebidas alcoólicas" foram o nicho escolhido para este trabalho, por apresentarem o idoso em ambientes diversificados como, por exemplo, ambiente familiar, bar e praia. Todos os comerciais da categoria correspondem a cervejas. Percebe-se também uma tendência dos anúncios de cerveja trabalharem questões de gênero, considerando seu público como predominantemente masculino. Portanto, este nos pareceu um nicho que possibilitaria observar e compreender o estereótipo do idoso, também envolvendo questões de gênero, apresentado em diversos locais e formas.

O aprofundamento proposto da análise do imaginário construído pela mídia sobre os idosos, corresponde, nesta pesquisa, a uma análise semiótica. Os critérios utilizados foram baseados nos trabalhos de Santaella (2002) partindo da avaliação de características físicas, comportamentais, de seleção de elenco, vestuário e cenográficas que pudessem estabelecer conexão com o imaginário identificado dos idosos. As razões da escolha dessa referência foram: a adoção, nos atuais cursos de Design da UEMG, do modelo ternário (signo, objeto, interpretante) desenvolvido por Pierce; a apresentação nessa obra de casos em diversos campos de aplicação, especialmente na publicidade, mídia e vídeos, coincidindo com nosso material de análise.

A autora delimita três pontos de vista semióticos como os ideais para se realizar uma análise do potencial comunicativo, sendo eles: o qualitativo-icônico, o singular-indicativo e o convencional-simbólico.

Segundo a autora, o ponto de vista qualitativo-icônico trabalha com a primeira impressão. Qual é a imagem ou ideia associativa que a marca desperta. Dentro desse ponto de vista se encontram as cores, linhas, volumes, dimensões, texturas, luminosidade, composição, forma, design, entre outros. Podem ser também qualidades abstratas como, leveza, sofisticação, fragilidade, pureza, severidade, elegância, delicadeza, força, monotonia, entre outros.

A partir do ponto de vista singular-indicativo, o produto é analisado como algo factual, realmente existente, segundo o contexto ao qual pertence, com índices de seu ambiente de uso, tipo de usuário/ consumidor que se destina, funções, finalidades entre outros. O produto também é analisado segundo a função que desempenha e sua finalidade. Ele é observado e examinado como sendo algo que existe em um espaço de tempo determinado, sendo visto a partir de sua manipulação e uso.

Por fim, ainda segundo a autora, no ponto de vista convencional-simbólico, o produto é analisado no seu caráter de tipo. Observa-se aqui seu design e padrões de gostos e quais expectativas culturais ele preenche. Seguindo a isso, se analisa o que ele representa, quais são os valores agregados, status, e como o produto contribui para a consolidação da marca. Por último, é analisado o tipo de usuário ou consumidor que o produto visa conquistar. Aqui tratamos as possibilidades de interpretação, que são acessadas pelo conhecimento prévio, pelo repertório também chamado por Peirce de "experiência colateral". 


\title{
3 Análise Semiótica
}

Seguindo esses pontos de vista, será efetuada a análise semiótica de cada uma das propagandas separadamente, com especial atenção à imagem do idoso. O material utilizado, que corresponde a anúncios de 3 marcas de cervejas, corresponde à totalidade dos filmes publicitários veiculados no período de coleta (de 22/06/2016 a 22/08/2016) da categoria "bebidas alcoólicas"

\subsection{Itaipava}

A propaganda da Itaipava corresponde ao anúncio criado pela $Y \& R$, em maio de 2016, com o título "Nova Lata", com o objetivo de mostrar os diferenciais do novo rótulo. O pequeno filme de trinta segundos, tem a participação da personagem Verão, interpretada por Aline Riscado (bailarina, garota propaganda da marca), além dos personagens: salva-vidas, amigos no happyhour, trio de ruivas, pescador e garçons.

A narrativa da propaganda (cujas cenas são representadas na Figura 1) é única sendo composta pela seguinte fala da protagonista (que aqui foi intercalada com a identificação das respectivas cenas):

\begin{abstract}
"A Itaipava está com uma nova embalagem inspirada no verão [cena1]. Eu adorei, porque tem o dourado da minha pele [cena2]. O salva-vidas porque tem selo de proteção [cena3]. Eles por causa do branco, afinal happy hour não pode passar em branco [cena4]. Elas por causa do vermelho [cena5]. 0 pescador gostou, e acredite, é verdade [cena6]. O Carlão porque os clientes vão gostar e para ele cliente é rei, e rei usa coroa [cena7]. Quem é do verão vai adorar [cena8]. Itaipava, a cerveja 100\%. Beba com moderação [cena9]."
\end{abstract}

Figura 1: Imagens correspondentes às cenas do anúncio da Itaipava

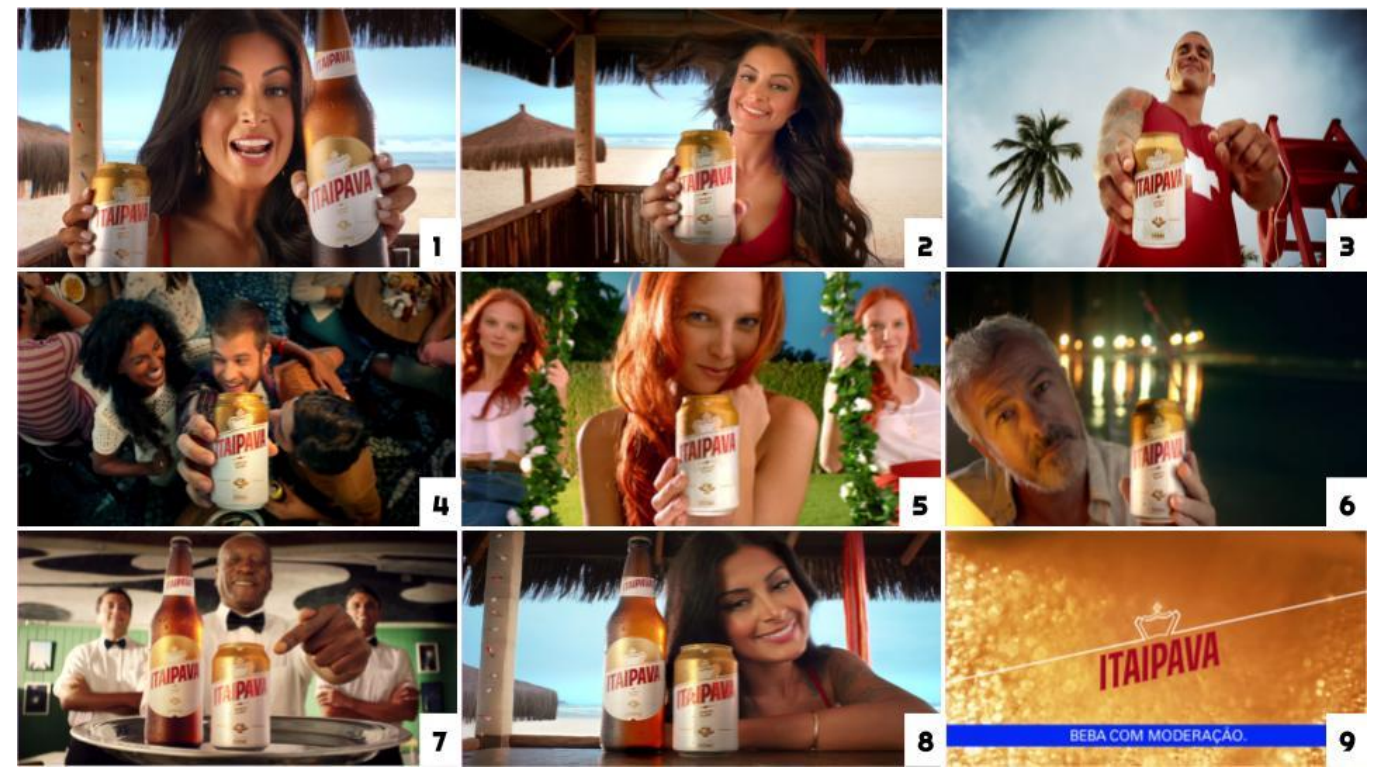

Fonte: Anúncio Itaipava

Analisando o anúncio do ponto de vista qualitativo-icônico, considerando elementos como cores, as formas e distribuição, observa-se o uso constante da cor vermelha para remeter à marca,

\footnotetext{
${ }^{1}$ Detalhes da metodologia de coleta em "Design e o Imaginário Construído sobre os Idosos" (PEREIRA; MENDONÇA, 2016).
} 
que a usa em seu logotipo para a grafia de seu nome. Essa cor foi trazida em vários momentos no anúncio como, por exemplo, nas roupas da personagem Verão e do salva-vidas e na cor do cabelo das personagens secundárias. A cor vermelha permite também uma leitura qualitativa trazendo impressão de calor, vigor e vitalidade.

Em relação à harmonia na composição das cenas, nota-se que o peso visual é sempre igual dos dois lados do eixo vertical central, buscando-se um equilíbrio imagético, e que a cerveja, elemento foco do discurso, é sempre colocado ao centro. Do ponto de vista da Semiótica, a qualidade a ser transmitida é principalmente a importância. Para transmitir esse valor, utiliza-se também de princípios da Gestalt ${ }^{2}$ para se criar bons conteúdos visuais. Aqui, os princípios de semelhança e proximidade criam composições simétricas e agradáveis. Um exemplo disso é a cena das ruivas e a dos garçons onde, além de ter um personagem centralizado, esse personagem está sempre segurando uma cerveja, colocada em uma posição central estratégica em relação à cena levando o observador a focar nesse local.

Já na leitura desse anúncio a partir do ponto de vista singular-indicativo, o primeiro ponto a se notar é que o seu objetivo é apresentar a "Nova Lata", que dá título ao anúncio. Os clientes devem reconhecer o produto com a nova embalagem. A narrativa do anúncio denota que a embalagem e seu rótulo têm características para agradar a vários públicos que são seus consumidores em potencial e as ocasiões/ lugares onde é usado o produto. Eles mostram que seus clientes podem ser jovens ou mais velhos, homens ou mulheres, que consomem o produto na praia, num quintal com balanço e gramado, em festa ou bares, a todo momento. A estação é sempre o verão que remete a calor, sede, necessidade de produto refrescante, com o qual o cliente se identifica.

Mas o foco da marca é mostrar que seus clientes têm um vínculo com a marca, uma identificação, que é a todo tempo relacionada na narrativa do anúncio. Para isso os pontos de vista convencional-simbólico também são explorados. De dia, ao sol, a morena sensual se identifica com o produto pela cor dourada da pele e o salva-vidas forte pelo valor que dá à segurança. Em ambiente fechado, ao final do dia, os amigos que não deixam de aproveitar a ocasião de comemorar (utilizando a associação da cor branca com a expressão idiomática "passar em branco"), também se identificam com o produto. Aqui, a simbologia do "branco", que remete à falta de ação, à folha em branco, onde nada foi escrito, contribui para a formação e significação desta expressão idiomática. Num ambiente mais privado e "fresco" (que o verde da vegetação remete), as ruivas com "olhar tímido" se identificam com o produto pelos elementos de similaridade com vermelho do seu cabelo. 0 produto tem seu lugar, inclusive à noite, quando o pescador, que tem a praia como seu ambiente de trabalho, demonstra gostar do produto. Apesar da associação culturalmente existente de "caso de pescador" com mentira e exagero, o anúncio diz que ali se tem um indício da qualidade do produto, pois o pescador está falando verdade ao dizer que gosta do produto. O garçom, em um ambiente público fechado (bar), se identifica quando associa o quanto valoriza o cliente com o tratá-lo como um rei (novamente uma expressão idiomática, que se refere a uma pessoa importante, que tem poder e por isso é servido, e atendido em suas necessidades, desejos e ordens), então reconhecendo essa significação de "realeza" na imagem de coroa existente no rótulo.

\footnotetext{
${ }^{2}$ Os pesquisadores da Gestalt, embasaram-se nos estudos psicofísicos relacionando a forma e sua percepção, para entender os processos psicológicos envolvidos na ilusão de ótica, onde o estímulo físico percebido pelo sujeito possui uma forma diferente em relação à realidade.
} 
Isso também pode ser observado na aparição do garçom e na fala "O Carlão porque os clientes vão gostar e para ele cliente é rei, e rei usa coroa". Nesse momento a narrativa coloca uma característica do rótulo da marca, que é a coroa, para criar um elo entre o personagem (garçom) e sua participação na iniciativa de fazer chegar ao cliente o melhor produto. $O$ dourado ganhou espaço na embalagem, assim como a coroa representada com traços particulares, escolhida como símbolo da cerveja, que nasceu em Petrópolis, e leva o nome de um seu distrito e de um bairro (Itaipava). Além da coroa simbolizar importância, objeto precioso e ter a mesma cor do produto em si (cerveja dourada), existe ainda a associação ao fato histórico que Petrópolis foi, de fato, Capital Imperial, e é uma cidade de água puríssima, insumo fundamental da boa cerveja.

A propaganda como um todo mostra os vários tipos de público da marca, nos interessando especialmente aqui analisar como é utilizada a imagem do idoso dentro do anúncio. Em um primeiro momento a idade do personagem é abordada na imagem do pescador, um ator branco de cabelos grisalhos. Apesar, do personagem trazer alguns traços característicos do estereótipo do idoso (rugas e cabelos brancos), ele aparenta estar nos seus 50 anos, ainda abaixo da faixa etária determinada como idoso.

$\mathrm{Na}$ aparição desse personagem, a pessoa de mais idade aparece como pescador, associado a um texto que remete à sua relação como um tipo de pessoa mentirosa, exagerada, não muito confiável. Essa característica contradiz com as qualidades normalmente atribuídas com o avançar da idade, que são a maturidade que traz confiabilidade, seriedade. A associação pescador e maturidade traz sentido para o texto "acredite, é verdade".

Também o garçom é retratado como uma pessoa de mais idade, aparentemente no início dos seus 60 anos. A escolha de um idoso para essa cena, pode estar conectada à imagem de serenidade e amabilidade atribuídas ao idoso, conforme Ribeiro (2007) o caracteriza. Já em um segundo momento, a associação de um personagem negro e o uso da qualificação de rei pode ser interpretado como um indício que o garçom, de nome conhecido (Carlão) seja baiano. De forma corrente, mesmo não sendo aceito pela totalidade das pessoas, reconhece-se o uso do predicativo "rei" como um modo de dizer típico do baiano, para valorizar o interlocutor, expressando afeto, carinho, respeito, atenção. Além disso, segundo o senso 2010 do IBGE, a Bahia é o estado com maior número de pessoas que se auto declaram negras (Portal Brasil, 2012). Considerando as características atribuídas ao idoso, é justificável o uso de um personagem idoso nesse momento passando confiabilidade, transmitida por sua experiência e sabedoria. Outro elemento que mostra a importância do idoso nesse anúncio e que traz também um aspecto de familiaridade, é o fato de ele ser o único personagem, além da protagonista, que ganha um nome específico, o que lhe dá destaque em relação aos outros. Os outros dois garçons ao fundo, brancos e mais jovens, têm uma postura de quem concorda e apoia a opinião do Carlão.

Esta postura do garçom idoso, que provoca simpatia no espectador, serve também como contraponto à tradicional associação das cervejas com um contexto machista, rejeitada por muitos, que coloca os homens como clientes principais, e as mulheres, que têm participação secundária enquanto consumidoras, como figuras bonitas, sensuais e atraentes, como a própria protagonista da Itaipava, a Verão. A propósito é oportuno notar que o nome Verão consiste em um jogo de associação da estação do ano, verão, quando o produto é preferivelmente consumido, com o nome próprio Vera, utilizado no aumentativo, fazendo referência ao "mulherão", que significa exatamente uma mulher de grandes atributos sensuais. Toda a simpatia atribuída ao idoso, representado pelo Carlão, vem reforçar que a cerveja agrada a todos os perfis. 
O próprio slogan da cerveja, "Itaipava - a cerveja 100\%", reitera a abrangência que o produto procura atingir bem como a sua "perfeição" enquanto produto. E o idoso se apresenta explicitamente como um grupo da sociedade.

\subsection{Kaiser}

A segunda propaganda da amostragem é da Kaiser, e tem por título "Sogro". O anúncio é da agência Talent Comunicação e Planejamento S/A, criado em maio de 2015 junto com a campanha "Você é o cara. Você é Kaiser", que teve como um dos objetivos exaltar a identidade masculina. $\mathrm{O}$ filme tem a duração de trinta segundos, apresentando como personagens o sogro e o genro, protagonistas do anúncio, além da filha, que logo no início sai de cena. Não há nenhum personagem de renome sendo apresentado apenas por atores desconhecidos.

O anúncio retrata uma pequena história onde o genro vai conhecer o sogro, e fica na indecisão de pedir a ele uma cerveja ao invés da bebida "esquisita" servida por ele. Dentro dessa indecisão ele discute com "as bolas".

Figura 2: Imagem com cenas do anúncio da Kaiser

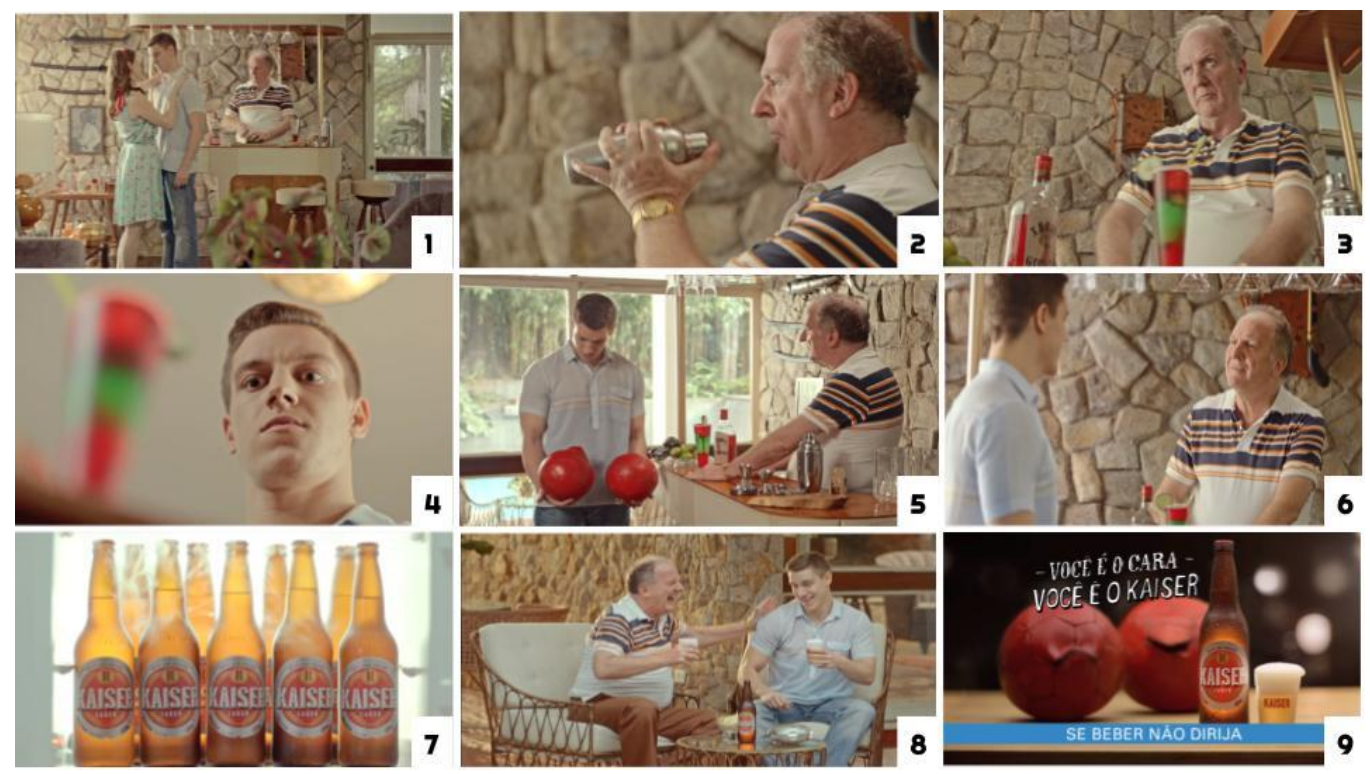

Fonte: Anúncio Kaiser

A narrativa e diálogos (cujas cenas são representadas na Figura 2) é a seguinte (que aqui foi intercalada com a identificação das respectivas cenas):

Namorada: Já volto amor. [cena1]

Narrador: Foi conhecer o sogro e ele serviu um drinque esquisito? [cenas2 e 3] Ainda bem que você tem suas bolas. [cena4]

Bola 1: Ô Edú, que bebidinha é essa aí? [cena5]

Bola 2: Podia rolar uma Kaiser, pô.

Genro: Mas eu acabei de conhecer ele. Fica chato.

Bola 1: Ah! Chato é você pegar a filha do companheiro aí.

Bola 2: Xiiii (pedindo silêncio) Você é um homem ou... xarope de groselha?

Bola 1: Vai, groselha.

Genro: O senhor não teria uma cerveja não?

Sogro: Gostei. [cena 6]. **Entra trilha de ópera quando abre um freezer de Kaiser** 
Narrador: Pensar como homem não é perfeito, [cena7] mas é isso que nos torna incríveis. [cena8]

Bola 1 e 2: Você é o cara. Você é o Kaiser. [cena9]

Analisando o ponto de vista qualitativo-icônico, considerando as cores, as formas e seu uso, nota-se que as cores pasteis foram usadas na ambientação como fundo de elementos mais importantes para a cena para os quais foi utilizada a cor vermelha, dando-lhes destaque. Este é o caso das bolas e da bebida. $O$ vermelho faz também referência à cor da marca Kaiser, que usa essa cor em sua tipografia.

Do ponto de vista singular-indicativo, a partir da própria narrativa do anúncio, podemos afirmar que o público alvo da marca é o masculino. A proposta do comercial é resgatar os códigos masculinos, acessando a sua consciência e reconhecendo os seus valores - confrontar os códigos do homem de 40 anos atrás, de provedor, protetor, com os novos valores atuais, tornando-se mais participante e sensível. $O$ anúncio pretende estimular seu público a se posicionar entre esses dois perfis, colocando seus valores com personalidade.

A ênfase ao público masculino é explicito em todo enredo da propaganda, já que o foco fica na conversa entre genro e sogro fazendo referência à expressão "conversa de homem", já que não é dada nenhuma importância para a jovem que, apesar de ser diretamente interessada no resultado do encontro entre seu pai e seu namorado, aparece rapidamente logo no início do anúncio, deixando os dois conversarem a sós.

A partir de uma leitura simbólica, também a metáfora das bolas é uma referência forte a esse universo. As bolas chamam o rapaz com seu apelido, o que remete à intimidade existente entre eles. Ainda uma interpretação possível é que o vermelho das bolas, além de dar destaque a elas, é usado como referência de pele ou mucosa que, na realidade, teriam um tom mais rosado, mas que aqui usa um tom mais forte para associá-lo a vigor másculo. A própria posição que o rapaz usa para segurá-las faz referência à posição dos órgãos genitais masculinos que o simbolizam.

Interessante notar que as bolas utilizadas no anúncio, factualmente, são do modelo Telstar, produzida pela Adidas, primeira bola oficial usada na Copa do Mundo FIFA, com estreia na Copa do Mundo de 1970, e também usada na Copa do Mundo de 1974. Assim, representam também tradição pelo seu modelo; mas ao assumirem a cor vermelha (ao invés das cores tradicionais preto e branco), transmitem a ideia de mudança e personalidade. As bolas também fazem referência à expressão "ter bolas", que se refere à caracterização masculina dos testículos e a qualidade atribuída ao homem de ser corajoso, aceitar desafios, aguentar revezes e enfrentar situações difíceis.

Ainda é uma interpretação possível que o personagem criado, as bolas, se refira à consciência do rapaz conversando com ele a todo o tempo, encorajando-o a tomar uma atitude. $O$ mais interessante nesse contexto é que a reação do sogro à atitude do rapaz, diferente do que ele esperava, foi de aprovação e mesmo incentivo, nascendo aí a identificação entre os dois.

Observando o ponto de vista singular-indicativo é importante colocar que todo o cenário foi escolhido de modo a combinar com a história de uma jovem levando o namorado para conhecer o pai. 
O ambiente é a casa do sogro, que tem uma decoração/ acabamento típicos das últimas décadas do século XX, com paredes de pedra almofadada e decoradas com armas e fotos que sugerem as atividades esportivas (e o "perigo" em potencial) do sogro (armas, peixe empalhado, sua foto em uniforme de judô), além de um balcão/ barzinho. Esses elementos, junto com os trajes do sogro e seu relógio de pulso dourado, remetem a seus atributos/ valores que são a esportividade, masculinidade, tradição, conservadorismo.

A sala, é o cenário inicial, ambiente de cerimônia, para visitas, simbolizando o distanciamento entre os dois. Ao final, quando foi estabelecida a camaradagem entre os dois, e se tornaram mais próximos, mesmo se ainda num contexto geral com os mesmos elementos decorativos tradicionais, eles passam a utilizar a varanda, ambiente mais descontraído e familiar.

A propaganda como um todo tem como foco mostrar para o homem que ele deve ser ele mesmo, sendo fiel aos seus gostos e valores. Que deve ser autêntico mostrando seu gosto pela cerveja e que a pessoa mais importante é ele mesmo, como indica o slogan "Você é o cara. Você é a Kaiser", utilizando o nome da cerveja, Kaiser, que também significa "imperador russo", que remete à importância, autoridade.

Considerando então o ponto principal do nosso interesse nesse trabalho, que diz respeito a aspectos da idade, notamos que a publicidade utiliza dois personagens; o sogro, mais velho e o genro, mais jovem. Inicialmente existe, da parte do mais velho uma desconfiança e descrédito no mais jovem, e da parte do mais jovem uma expectativa que chega ao nível do medo, não só pela idade, mas pela autoridade e poder por ser pai da sua namorada e os seus valores poderem interferir no relacionamento dos dois. O mais velho é colocado na posição de poder julgar, aprovar ou reprovar o mais jovem, facilitar ou dificultar a vida do casal.

O idoso representa então o tradicional, conservador, a seriedade, bem como autoridade e poder em relação ao jovem. O jovem carrega consigo as inseguranças do homem, moldadas por algumas convenções sociais. Por outro lado, os costumes sociais se apresentam em mudança - o rapaz tem relacionamento íntimo com a namorada ("pegar"), o que era um tabu no período de juventude do sogro. $O$ idoso, assim, também se apresenta como uma pessoa que teve seus desejos reprimidos por convenções sociais durante a juventude.

A ideia de pessoa conservadora é quebrada quando o sogro demonstra que gostou da atitude espontânea do jovem, aparecendo logo depois uma cena com os dois bebendo juntos e alegres, em clima de camaradagem. Isso demonstra que o idoso atual consegue manter a essência do "ser homem" sem ser fechado ou careta. Mostra que, muitas vezes, o distanciamento entre gerações é mais uma questão de preconceito social do que uma realidade. Que existem, na realidade, mais valores em comum entre gerações, do que diz senso comum e que esta convivência é benéfica para todos. A contraposição "jovem x idoso" é mais um estereótipo que uma realidade, sendo o idoso capaz de se comunicar e viver as experiências dos dias atuais, inclusive se divertindo junto com o jovem (mesmo que seja outro estereótipo o "tomar cerveja" como sinônimo de diversão masculina). Outra interpretação possível é que respeito não é antagônico ao divertimento e não é sinônimo de medo.

\subsection{Proibida}

A terceira propaganda a ser analisada é a da "Proibida Puro Malte - A Cerveja 6 Estrelas", anúncio criado pela agência We. $O$ vídeo do anúncio publicitário dura trinta segundos, trazendo o 
ator nacionalmente conhecido, Antônio Fagundes, para apresentar o produto. A narração é toda feita pelo próprio ator, que fala com o público, e os demais personagens que aparecem são figurantes, representando jovens, homens e mulheres, em papeis de clientes e garçons.

Figura 3: Imagem com cenas do anúncio da Proibida Puro Malte
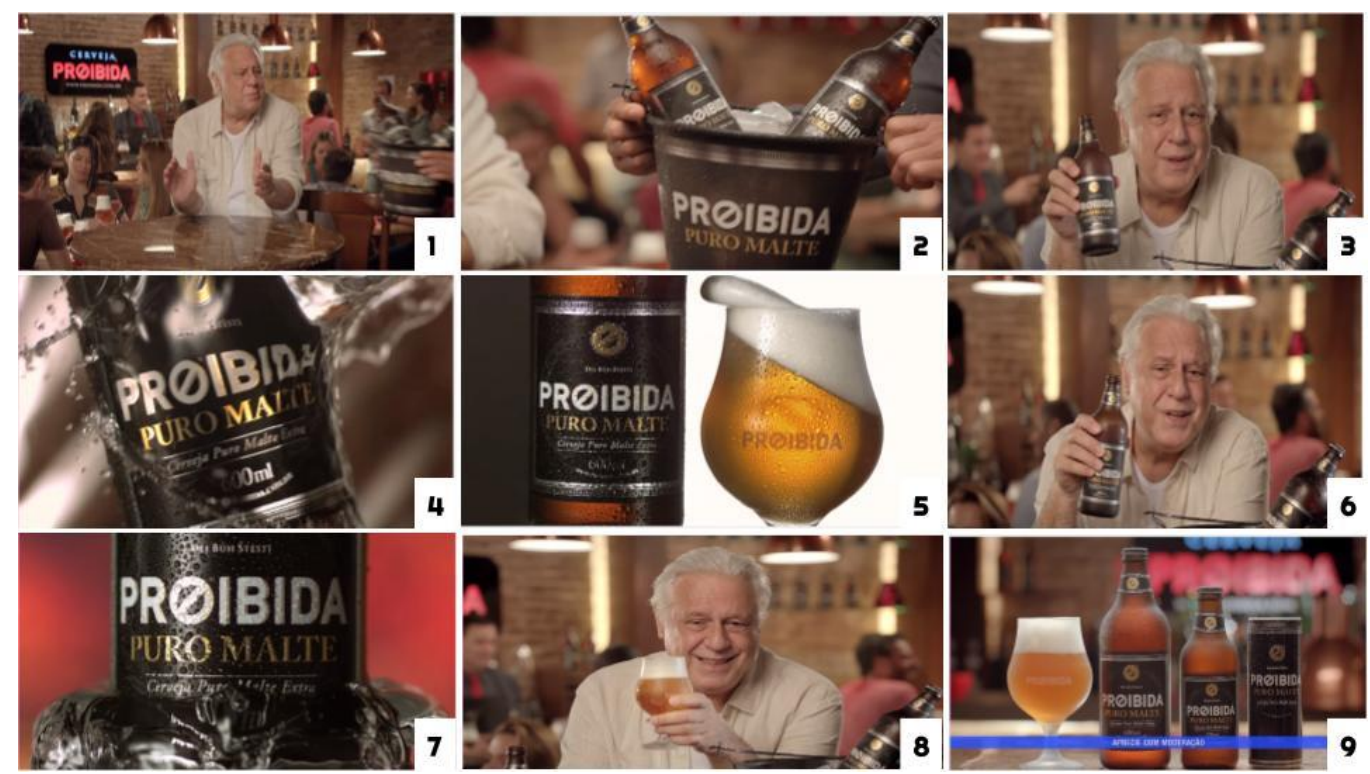

Fonte: Anúncio da Proibida

Enquanto narra, as cenas são focadas no ator e em alguns momentos no produto (garrafa, copo com cerveja, balde da marca, cheio de garrafas da cerveja)

A narrativa da propaganda (Figura 3) é única e objetiva, sendo composta pela seguinte fala (aqui intercalada com a identificação das cenas):

“Eu já provei muita cerveja na minha vida [cena 1], mas nunca me apaixonei por nenhuma [cena 2] até o dia que eu provei a Proibida Puro Malte [cena 3]. A Proibida Puro Malte é demais. [cena 4] É uma verdadeira cerveja 6 estrelas. [cena 5] Bebida Puro Malte é para quem gosta do melhor, por isso agora eu posso dizer com certeza, [cena 6] encontrei minha cerveja. [cena 7] Proibida Puro Malte a verdadeira 6 estrelas, como toda proibida é gostosa demais. [cena 8] " Narrador: Aprecie com moderação. [cena 9]

Do ponto de vista qualitativo-icônico, observa-se que a ambientação e as cores utilizadas são bem neutras, caracterizando um bar com um estilo despojado, sóbrio. Também o ator usa roupa de cores neutras. No plano aberto inicialmente apresentado, vê-se também ao fundo, uma placa em neon com texto azul e vermelho e fundo preto, com a marca da cerveja. As cores e a luz dão destaque à marca.

A cerveja Proibida Puro Malte, produto deste anúncio, também possui rótulo com cores neutras (branco, prata e dourado) com fundo preto. O fundo claro da roupa do ator e do ambiente dá contraste à cor âmbar escura da garrafa, dando a ela o devido destaque.

Depois da primeira cena, que contextualiza o ambiente de consumo da cerveja, as demais utilizam sempre o plano fechado, desfocando o fundo. Existe harmonia na composição das cenas, com peso visual equilibrado. Na maioria das cenas em que aparece o ator ou apenas a cerveja, sua 
imagem está centralizada, inclusive nas cenas em que foram trazidos mais de um elemento quando o equilíbrio centralizado foi obtido pela distribuição dos objetos. Além disso, a neutralidade das cores, bem como o ambiente onde as pessoas conversam com tranquilidade, sugerem sobriedade.

A placa em neon na parede do bar com o nome da cerveja em cores fortes coloca o ambiente com um certo grau de dedicação ao produto. A mesa do bar com tampo em mármore também indica a qualidade superior do ambiente e dos demais elementos que fazem parte do seu contexto. $\mathrm{O}$ ator Antônio Fagundes, como uma personalidade nacionalmente famosa, indica com suas atitudes, sua apreciação pela qualidade do produto, o que é reforçado pela sua fala.

O "suor" da garrafa e do copo, indicam sua temperatura gelada, refrescante, valor para quem aprecia cerveja. Também a água, presente em vários momentos, é um ingrediente de qualidade fundamental para a qualidade da cerveja e representa refrescância. Na cena da taça que desliza e toca na garrafa, o líquido se desloca em direção da garrafa e a espuma coroa este movimento, dando a impressão de uma espuma espessa, o que é intensificado pelos recursos da câmera lenta e do corte da cena antes que a espuma derramasse. A espuma é formada pelo gás carbônico e as proteínas contidas na cerveja. Quem é especialista afirma que ela é importante para a degustação da bebida, mantendo o sabor, o amargor que está presente nela. "Além disso, o colarinho ajuda a manter a temperatura da bebida no copo, e na liberação dos aromas. "3

Já do ponto de vista convencional-simbólico o produto é descrito como uma cerveja 6 estrelas. A classificação por estrelas é uma convenção utilizada para os meios de hospedagem, relacionada a atributos físicos e de serviço, que definem a qualidade de experiência do hóspede. No Brasil os níveis vão de 1 a 5 estrelas; desse modo 6 estrelas representaria a superação das expectativas do cliente. A própria empresa, em um outro anúncio, explica que " 5 estrelas" representam "o máximo" e então "6 estrelas" representam "o máximo para quem gosta do melhor".

O anúncio, no geral, deixa bem claro que seu intuito é afirmar que a cerveja Proibida seria a melhor cerveja puro malte, fazendo o uso de uma personalidade famosa e respeitada para, como uma "autoridade", intensificar e dar credibilidade a essa afirmativa. O ator Antônio Fagundes na época em que fez o comercial estrelava uma novela de televisão tendo, portanto, uma grande visibilidade nacional naquele momento. Como um ator famoso, Antônio Fagundes traz confiabilidade às suas afirmações e leva a pensar que, sendo um profissional de sucesso, as escolhas que faz são acertadas, e segui-las traria bons resultados também para o espectador.

Analisando o imaginário do idoso, Antônio Fagundes estaria representando o charme além do tempo e da idade. Famoso no cinema, teatro e TV há mais de 40 anos, a idade não traz atributos negativos para ele. Seus cabelos brancos são considerados como elemento de charme, e a idade associada a experiência, sabedoria, confiabilidade. Os longos anos representam capacidade de permanecer com sucesso e, portanto, Ihe conferem uma chancela de capacidade e inteligência para tomar boas decisões. Para o produto, ter uma pessoa com esses atributos dizendo ser apaixonado por ele, funciona então como uma garantia da sua qualidade superior.

\footnotetext{
3 "Com espuma: saiba por que o colarinho faz bem para a cerveja". Disponível em <http://g1.globo.com/especialpublicitario/somos-todos-cervejeiros/noticia/2016/01/com-espuma-saiba-por-que-o-colarinho-faz-bem-paracerveja.html>.
} 
Como nos anúncios já analisados das outras cervejas, também nesse caso tem um forte cunho machista. O nome da cerveja "Proibida", já traz a valorização da emoção de se fazer algo errado, proibido, e a palavra ser usada no feminino, traz ainda uma conotação de infidelidade. Como ator, Antônio Fagundes representa personagens viris, atraentes e desejados pelas mulheres. Nesse comercial o ator, com sua fala "...como toda proibida é gostosa demais", insinua um estímulo à infidelidade querendo dizer ser essa postura mais prazerosa e se refere à abordagem à mulher com a "cantada" que a chama de "gostosa". Nesse contexto politicamente incorreto, mas que se considera ser valorizado pelo público masculino (principal público dessa cerveja, conforme inclusive explicitado em outro comercial da marca), ter um artista "maduro, confiável e simpático" serve também como um contraponto para amenizar a sua fala comercialmente agressiva, e reduzir a rejeição por parte de outros segmentos de clientes.

\section{Resultados}

Tomando como referência os comerciais de cervejas, foram confirmadas e identificadas algumas características atribuídas aos idosos: rugas, cabelos brancos, confiabilidade, seriedade, serenidade; valorização do interlocutor, expressão de afeto, carinho, respeito, atenção; experiência, sabedoria, amabilidade. Ele pode aparecer também como representante de charme atemporal, maturidade e simpatia. Interessante notar que, em um setor normalmente voltado aos jovens homens, em um contexto machista, o idoso aparece como contraponto simpático.

O idoso, mesmo no mercado das cervejas que se posiciona num contexto de saúde, força, animação, diversão, é reconhecido como um dos segmentos da sociedade (do mercado) e, numa análise semiótica, faz aflorar algumas questões, além das mais óbvias já mencionadas.

Uma delas é o relacionamento entre gerações. Observa-se que existe uma questão de desconfiança e descrédito no mais jovem por parte dos mais velhos num posicionamento tradicional, conservador, de seriedade e autoridade, que gera, mais do que respeito, medo, por parte do mais jovem. Assim, reunir diferentes gerações com diferentes níveis de experiência e energia às vezes parece problemático, como descrevemos também em nossa pesquisa anterior ${ }^{4}$. 0 mais experiente tende a dominar e os jovens a se sentirem subjugados e explorados. Mas, como constatamos, o idoso é capaz de se atualizar e o acolhimento à diversidade é um valor importante para a sociedade. 0 mais velho tem o valor da experiência de vida e de ter experimentado uma gama variada de situações e acumulado conhecimento e o mais novo tem energia, é curioso e está em seu processo de construção e crescimento. Esta constatação pode levar a novos arranjos de equipes de trabalho, que valorizem a diversidade, o melhor potencial de cada um, e papeis que minimizem conflitos. Diversidade de áreas de conhecimento, energia e experiência é valioso para equipes produtivas.

Uma outra questão é que envelhecimento não é uma característica homogeneizadora. 0 processo normativo de envelhecimento traz características senescentes, isso é, características que são o resultado de mudanças orgânicas, funcionais e psicológicas do envelhecimento. Como algumas mudanças, pode-se notar a redução do batimento cardíaco no repouso, redução da função pulmonar, redução do comprimento, elasticidade e número de fibras do sistema músculo esquelético, além da diminuição do número de neurônios, da velocidade de condução dos nervos, da intensidade dos reflexos e restrições de respostas motoras. No entanto, apesar de um certo

\footnotetext{
${ }^{4}$ Análise sistêmica do Projeto Canavese Connexion (MENDONÇA, 2014).
} 
nível de perdas ser inevitável, essas mudanças ocorrem em maior ou menor grau, mais cedo ou mais tarde, em função também do estilo de vida de cada um.

Dessa forma, para que o idoso se sinta melhor nessa fase da vida é desejável que ele tenha um envelhecimento ativo. Diferente do que a sociedade entende como envelhecimento ativo e é explorado pelos comerciais, ele vai muito além de apenas manter os cuidados e praticar esportes para se ter uma boa saúde. O envelhecimento ativo permite que as pessoas percebam o seu potencial para o bem-estar físico, social e mental ao longo do curso da vida, e que essas pessoas participem da sociedade de acordo com suas necessidades, desejos e capacidades; ao mesmo tempo, propicia proteção, segurança e cuidados adequados, quando necessários. Além disso, o envelhecimento não nivela a todos e por isso existirão idosos ativos e fortes, bem como desestimulados e frágeis. Portanto o idoso, da mesma forma que aconteceria com outros grupos, deve ser observado e estudado de acordo com cada situação

Isso vem reforçar a importância da participação do usuário no processo de design. Ele pode ser envolvido desde a elicitação dos requisitos, do briefing, passando pelos testes ao longo do desenvolvimento do produto ou para validar a versão "quase final" do produto. Clientes são testadores valiosos, que devem ser envolvidos o quanto antes no processo de desenvolvimento, uma vez que é economicamente comprovado que quanto mais cedo o problema é encontrado, menos custosa é a sua solução (MENDONÇA, 2014).

Especificamente em relação aos idosos, como mostra este nosso estudo, seu envolvimento no desenvolvimento do produto não pode ser negligenciado por várias razões: pela sua crescente presença de mercado, pelo seu perfil complexo e rico em possibilidades. Compreender esta categoria de clientes abrirá diversas oportunidades de criação e evolução produtos e serviços.

Um outro ponto que é necessário ressaltar aqui é a importância do repertório do designer. No clássico "Designerly Ways of Knowing", Nigel Cross trata dessa questão, e conclui que o treinamento extensivo em um domínio ainda parece ser crucial para a perícia profissional (CROSS, 2007, p. 97) ${ }^{5}$ Este nosso estudo vem reforçar, agora do ponto de vista da Semiótica, essa necessidade. A riqueza dos interpretantes depende da cultura, das experiências e vivências daquele que interage com o signo. Essa relação do ponto de vista do profissional do design permite não só a percepção de necessidades e oportunidades de atuação, ao "ler" o contexto (físico e humano) da sua interferência, mas também ao perceber elementos da sua criação que possam proporcionar experiências valiosas e diferenciadas. Também a experiência ressalta a importância do uso de certas ferramentas, como a Ergonomia, favorecendo a eficiência do conjunto humano-produto-serviço.

Nesta análise feita, surgiram alguns elementos de dualidade, e seus estereótipos, como "jovem x idoso", "homem x mulher" (MORAIS et al., 2009). Contudo, foi possível identificar que o distanciamento entre polos é tratado de forma diferenciada entre as diversas culturas, com uma visão mais ou menos otimista, e a publicidade espelha isso.

Por tudo isso, o conhecimento do designer lhe permite atuar de forma positiva, não contra um ou outro gosto, uma ou outra postura, mas a seu favor, a favor de uma missão da evolução da nossa sociedade. Ele deve ter visão crítica e conhecimento suficientes para análises semióticas das informações que recebe. Trabalhar para a quebra dessas dualidades que possam ser formadas e

\footnotetext{
${ }^{5}$ Texto original "Extensive training within a domain still seems to be crucial to professional expertise".
} 
da confusão entre respeito e medo, diversão e desrespeito, construindo um contexto comum de convivência, produção e diversão pode ser a chave de um novo patamar de sustentabilidade social.

\section{Conclusão}

Nesse trabalho foi feita uma análise semiótica utilizando uma amostragem dos comerciais de TV veiculados em 2016, coletados e armazenados em nossa pesquisa anterior. Essa amostragem foi selecionada pela riqueza de detalhes e por serem anúncios provocativos. Também pelo inusitado da representação do idoso em um comercial que foca o público jovem.

Com a análise dos estereótipos dos idosos, buscou-se contribuir para uma compreensão do imaginário dos idosos na sociedade atual com o objetivo de contribuir para a eficiência nas atividades de marketing e publicidade que, direta ou indiretamente, subsidiam também as atividades de Design. A análise realizada permitiu a construção de algumas conclusões merecedoras de destaque.

Foi possível perceber que, para um determinado fato, existem vários interpretantes. A descrição do fato depende do ponto de vista, existindo diversas descrições para um mesmo fato, e todas podem ser verdadeiras. A riqueza dos interpretantes depende do repertório de quem interpreta. Quanto maior a sua experiência maior o número de possibilidades que um signo contém. Assim, é importante que o designer tenha uma formação completa e uma riqueza de experiências para utilizar os signos apropriadamente em seu trabalho.

Foi enfatizado que realmente existe uma diversidade de perfis de idosos. Isso reforça que sempre necessário conhecer o usuário e conseguir que participe do processo para elaboração de bons trabalhos, o que é especialmente verdadeiro em se tratando dos idosos e da sociedade atuais. A publicidade tem a peculiaridade de construir um imaginário pronto para ser socialmente difundido. Mas os bons profissionais que atuam tão de perto com questões culturais, podem, e devem absorver as ideias, perspectivas e sentimentos emergentes de uma sociedade ou grupo social, utilizando metodologias que o aproximem de quem de fato, irá utilizar a sua criação.

Os dados e análises realizadas expuseram a missão do designer no trabalho de compreensão dos fatores complexos que nos rodeiam, das possibilidades que existem na atuação colaborativa e do seu potencial de transformação da sociedade. Pode-se dizer que, da mesma forma que a publicidade, o design deve incorporar elementos que levem à compreensão das reais características dos idosos e de suas condições de vida a partir das alterações demográficas observadas e comentadas no início deste artigo. Compreender as verdadeiras necessidades e desejos da população idosa é um desafio do design e o abandono de estereótipos é um passo importante neste caminho.

\section{Referências}

ANTONIONI, Stefania; MAZZOLI, Lella. "Is that me?" Images of ageing and the underestimated role of active ageing in advertising. In: ISA WORLD CONGRESS OF SOCIOLOGY FACING AN UNEQUAL WORLD: CHALLENGES FOR GLOBAL, 18., 2014, Yokohama. Anais... Yokohama: International Sociological Association - ISA, 2014, p. 35 - 36.

CROSS, Nigel. Designerly Ways of Knowing. Berlin: Birkhäuser, 2007. 
KEARNEY, A.T. Understanding the needs and consequences of the ageing consumer. At Kearney, 2013. Disponível em: <http://www.atkearney.com/paper/-/asset_publisher/ $\mathrm{dVxv} 4 \mathrm{~Hz} 2 \mathrm{~h} 8 \mathrm{bS} /$ content/understanding-the-needs-and-consequences-of-the-ageingconsumer/10192>. Acesso em: Mar./ 2014.

EUROMONITOR. Elderly consumer in developed countries can provide an important source of growth. 2013. Disponível em: <http://blog.euromonitor.com/2013/01/elderly-consumers-indeveloped-countries-can-provide-an-important-source-of-growth-.html>. Acesso em: Mar./ 2014.

IBGE. Estimativas populacionais para os municípios brasileiros em 01.07.2013. 2013. Disponível em: < https://ww2.ibge.gov.br/home/estatistica/populacao/estimativa2013/estimativa_dou.shtm >. Acesso em: Mar./ 2014.

MENDONÇA, Rosângela Míriam L.O. Systemic Network Innovation and Its Application in the Brazilian Context of the Estrada Real. 2014. 218 f. Tese de Doutorado (Sist. de Prod. e Design Industrial) - Politecnico di Torino, Torino, Fev./2014.

MIRANDA-MORENO, L. F; LEE-GOSSELIN, M. A week in the life of baby boomers: how do they see the spatial: temporal organization of their activities and travel? Transportation. v.35, p.629, 2008.

MORAIS, Hellena B.; MACHADO, Amanda P.; LINK, Lucas G.; STREY, Marlene N. . A Psicologia e os estereótipos de gênero, 10., 2009, Porto Alegre. Anais..., Porto Alegre: Salão de Iniciação Científica - PUCRS, 2009. p. 1810 - 1812.

ORGANIZAÇÃO MUNDIAL DE SAÚDE. Resumo: Relatório mundial de envelhecimento e saúde. Genebra: Organização Mundial da Saúde. 2015. 30 p.

PEREIRA, Leandro Feu A.; MENDONÇA, Rosângela Míriam L. O. Design e o Imaginário Construído sobre os Idosos. In: SEMINÁRIO DE PESQUISA E EXTENSÃO DA UEMG, 18. , 2017, Belo Horizonte. Anais .... Belo Horizonte: UEMG, 2016.

Portal Brasil. Educação. Censo 2010 mostra as características da população brasileira. 2012. Disponível em:<http://www.brasil.gov.br/educacao/2012/07/censo-2010-mostra-as-diferencasentre-caracteristicas-gerais-da-populacao-brasileira>. Acesso em: Fev./2018.

RIBEIRO, António Pedro Freire. Imagens da velhice em profissionais que trabalham com idosos. 2007. 208 f. Dissertação (Mestrado em Geriatria e Gerontologia) - Universidade de Aveiro, Portugal. 2007.

SANTAELLA, Lúcia. Semiótica Aplicada. São Paulo: Thomson Learning, 2002. 186 p.

UNITED NATIONS. World Population Ageing. New York, 2009. Disponível em: $<$ www.un.org/esa/population/publications/WPA2009/WPA_WorkingPaper.pdf. Acesso em Mar./2016.

UNIVERSIDADE FEDERAL DE UBERLÂNDIA-UFU. O processo e o sujeito do envelhecimento. Uberlândia, 2012. 48 p. Disponível em: <http://www.afrid.faefi.ufu.br/sites/afrid.faefi.ufu.br/files /Doc/completo_8.pdf>. Acesso em: Nov./ 2013.

WORLD HEALTH ORGANIZATION - WHO. Envelhecimento ativo: Uma Política de Saúde / World Health Organization; tradução Suzana Gontijo. Brasília: Organização Pan-Americana da Saúde, 2005. 60 p.Disponível em: <bvsms.saude.gov.br/bvs/publicacoes/envelhecimento_ativo.pdf>. Acesso em: Abr./ 2013. 